\title{
Recognition of recalled and non-recalled items
}

\section{W. PACKHAM, DEPARTMENT OF PSYCHOLOGY, THE UNIVERSITY OF NEWCASTLE UPON TYNE, England}

An experiment was conducted to investigate whether the presence of previously recalled items in a recognition test affected $S s^{\prime}$ efficiency in discriminating items they had previously failed to recall. Two different tests of recognition were given to both groups of Ss after they had attempted free recall. Inclusion of recalled items in the first test significantly impaired overall recognition scores as compared with their inclusion in the second test only.

Brown (1965) has proposed a new version of a commonly used recognition test in which Ss have essentially to rank the alternatives from a recognition list consisting of previously presented items and new items (distractors). The items are normally ranked in descending order of their familiarity to the S: thus the item judged as most likely to have been presented previously is placed first and the item most likely to be a distractor is placed last. This multiple response test yields an overall recognition score, $\bar{A}$, in terms of the average probability of rejecting a distractor when selecting correct alternatives. $\bar{A}$ can vary between +1 and -1 and has a chance level value of 0 . One advantage of the measure is that it is sensitive to changes in the extent to which partial information is used by the $S$.

In a recent experiment (Brown \& Packham, 1967) a multiple response test was given in two stages in order to investigate whether an $\mathrm{E}$ group, after attempting recall, would subsequently be less willing to select items from a recognition list than a $\mathrm{C}$ group who had not attempted recall. A null effect was obtained, possibly because there was a strong tendency for Ss to pick out approximately $50 \%$ of the list in Stage 1 (cf. Belbin \& Cane, 1956). However, a more detailed analysis of the data showed that the $\mathrm{E}$ group tended to assign very low ranks to some of the items they had failed to recall, whereas the $C$ group rejected very few of the items originally presented to them. This finding was confirmed in a second experiment.

It follows that the mere presence of highly familiar recalled items in a recognition test may serve to lower the overall score. Accordingly, if Ss are given two consecutive tests, only one of which contains a sample of recalled items, then a difference should be revealed. In this case, it is possible either to keep the number of items in each test constant or to increase one of the recognition lists by the addition of recalled items. The latter has the advantage of providing a check on the tendency for Ss to attempt discrimination on only a restricted proportion of a list.

Method. The Ss were 24 undergraduate psychology students at the University of London. They were assigned alternately in order of arrival to one of two groups and tested individually. A cross-over design was employed such that, after presentation and recall, Group 1 attempted Recognition test A followed by Recognition test B, whilst Group 2 received these tests in the reverse order.

The material presented on slides consisted of $\mathbf{4 0}$ six letter words, randomly selected from the A category of the Thorndike-Lorge word count (1944). A Sawyer's Rotomatic projector and Mirascreen were used to present the sequence of words at a speed of one word per 5 secs. (As originally manufactured this projector has to be placed between the screen and the $S$. However, by resiting the bottom mirror in the Mirascreen, its position relative to the projector can be reversed, thereby allowing an unrestricted view of the display to the $S$.) The projection size of the words was $20 \times 3.5 \mathrm{~cm}$, with the $S$ seated some $2 \mathrm{ft}$ from the screen.

After presentation all Ss attempted written free recall for $5 \mathrm{~min}$. For recognition, samples were drawn from a pack of 60 playing cards, 40 printed with the same words as on the slides plus 20 cards and words from the same word count category, which acted as distractors. During recall and while Ss were reading the instructions for recognition, the $\mathbf{E}$ subdivided the cards into sets of recalled words, non-recalled words, and distractors. After shuffling each set Recognition test $A$ was made up by the $E$ dealing five recalled words,
10 non-recalled words, and 10 distractors and then reshuffling. Recognition test $B$ differed by the exclusion of recalled words and previously used cards.

The Ss were instructed to sort the cards along the old-new dimension of familiarity at their own speed and into four piles initially, viz:- (i) definitely presented (ii) probably presented (iii) probably not presented and (iv) definitely not presented; then to revise the order of each pile where they thought it necessary. Ss received the second pack of cards on returning the first pack to the E. Approximately $3 \mathrm{~min}$ was taken for each recognition test.

Results and Discussion. The recall scores of the two groups did not differ significantly $(\mathrm{t}<1.00)$ but their recognition scores, illustrated in Fig. 1 , show a marked superiority $(\mathrm{t}=3.67, \mathrm{df}=22$, p $<0.002$ ) in favor of Group 2 who received Recognition test B first. For the purposes of this comparison, only the non-recalled words in both tests were scored, although subsequently the performance of the two groups on the recalled words in Recognition test A was compared. Not suprisingly it was at a high level for all Ss, and no difference was obtained $(t<1.00)$. Similarly the remaining comparisons between orders of testing and types of test did not yield significant results.

These findings permit some clarification of Kay \& Skemp's (1956) hypothesis that strong associations can depress weaker ones. In choosing between various interpretations of this hypothesis discussed by Brown \& Packham (1967), it is worth noting that a decline in $\bar{A}$ cannot be directly interpreted as evidence for a criterion shift because its possible effects are eliminated by the multiple response test. $\bar{A}$ is lowered only when more distractors on average are preferred to correct items. If an explanation in terms of criterion shift is to be retained, an additional assumption must be made. For instance, Group 1 Ss may give up their attempt to make discriminations relatively early in Recognition test A. that is, while they are still able to make further correct discriminations. Yet it is difficult to see why the same process should not occur with Group 2 when faced with Recognition test A. There was no clear evidence that $S s$ attempted discrimination on a restricted proportion of the test items.

It seems more likely that Group 1 Ss were using an inappropriate scale for their judgments throughout. The initial presence of highly familiar recalled words could convey the impression that crude judgments were required for the experimental task, whereas in fact fine ones were needed to separate the non-recalled words

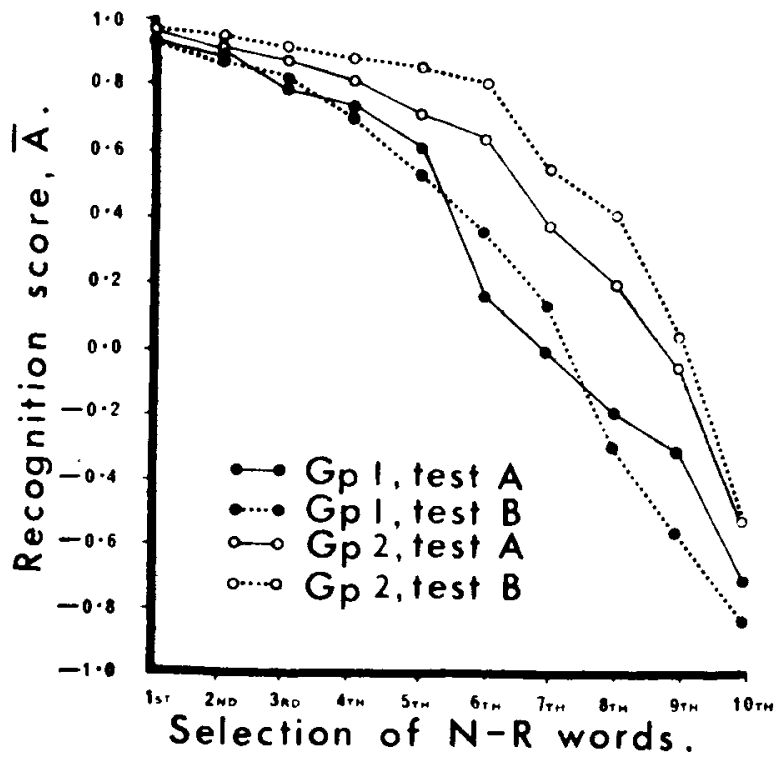

Fig. 1. Values of $\vec{A}$ for successive non-recalled words selected. 
from distractors. This is similar to an interpretation of Kay and Skemp along the lines of threshold shift, where a fall in threshold might bring a marginal association above threshold and vice-versa. However, it emphasizes the role of Ss' set rather than associative strength in determining their efficiency in discriminating relatively unfamiliar items.

\section{REFERENCES}

BELBIN, E., \& CANE, V. R. Some factors affecting response in recognition tests. Quart. J, exp. Psychol, 1956, 8, 45-53.

BROWN, J. Multiple response evaluation of discrimination. Brit. J. math. statist. PsychoL, 1965, 18, 125-137.
BROWN, J., \& PACKHAM, D. W. The effect of prior recall on multiple response recognition.Quart. J. exp. Psychol., 1967, 19, 356-361.

KAY, H., \& SKEMP, R. Different thresholds for recognition-further experiments on interpolated recall and recognition. Quart. J. exp. Psychol., $1956,8,153-162$.

THORNDIKE, E. L., \& LORGE, I. The teacher's word book of 30,000 words. New York: Columbia Univ. Press, 1944.

\section{NOTE}

1. This experiment was conducted at Birkbeck College, University of London, while the author was in receipt of a Science Research Council award. 